\title{
Erratum: Modulation of mRNA and IncRNA expression dynamics by the Set2-Rpd3S pathway
}

Ji Hyun Kim, Bo Bae Lee, Young Mi Oh, Chenchen Zhu, Lars M. Steinmetz, Yookyeong Lee, Wan Kyu Kim, Sung Bae Lee, Stephen Buratowski \& TaeSoo Kim

Nature Communications 7:13534 doi: 10.1038/ncomms13534 (2016); Published 28 Nov 2016; Updated 29 Nov 2017

The ArrayExpress accession code is incorrect in this Article. The correct accession code is E-MTAB-4268.

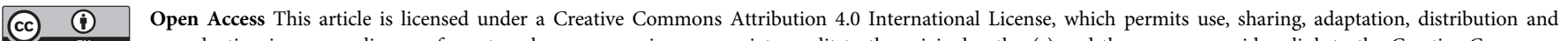
reproduction in any medium or format, as long as you give appropriate credit to the original author(s) and the source, provide a link to the Creative Commons

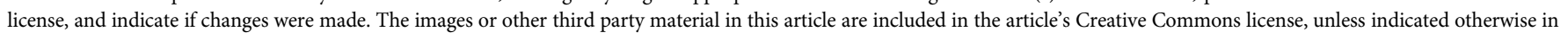

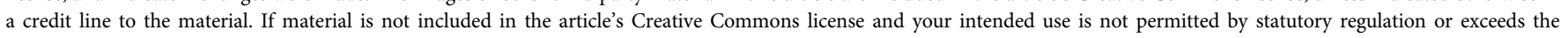
permitted use, you will need to obtain permission directly from the copyright holder. To view a copy of this license, visit http://creativecommons.org/licenses/by/4.0/

(C) The Author(s) 2017 